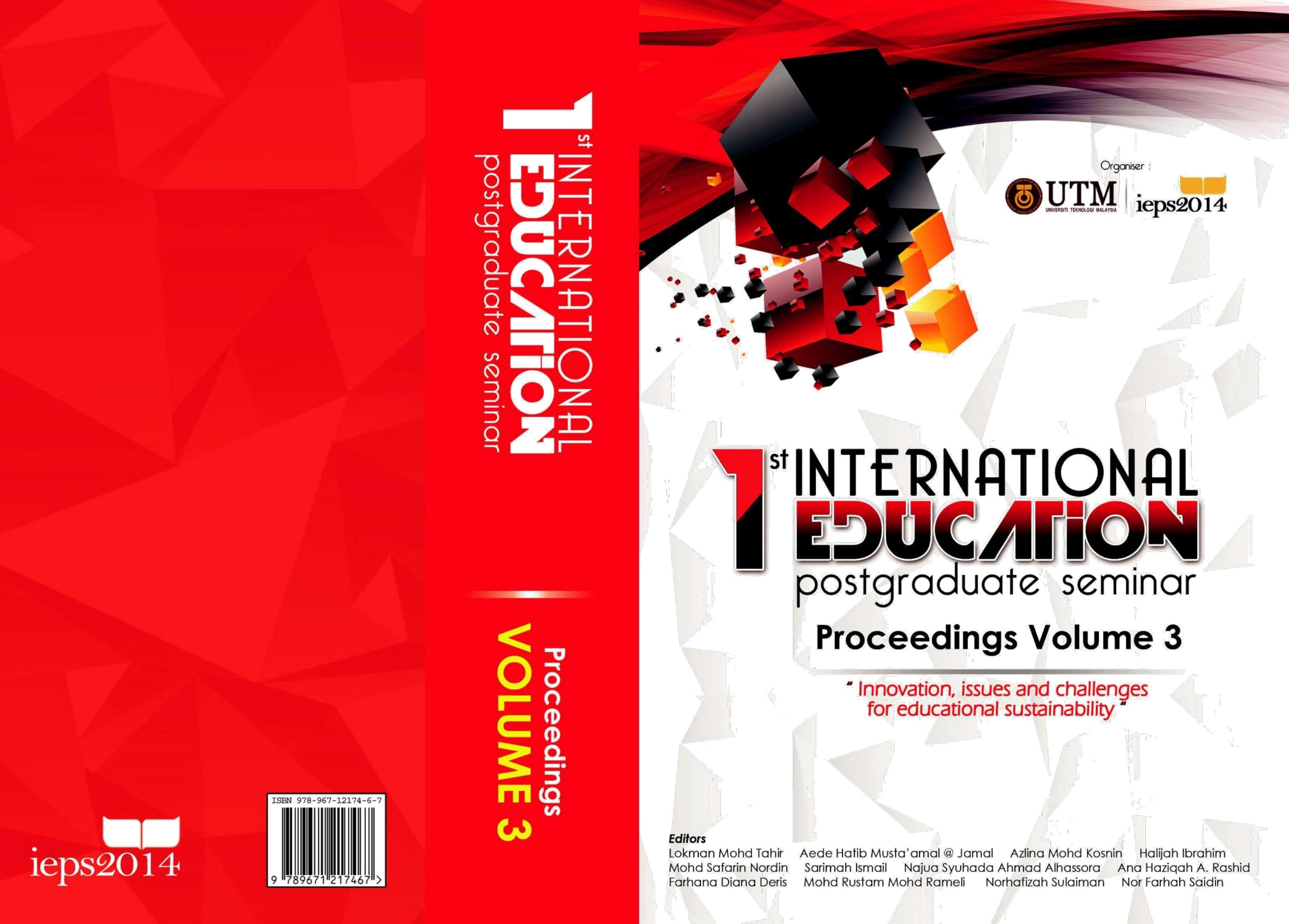




\section{IEPS2014}

International Education Postgraduate Seminar 2014

23-24 December 2014

Universiti Teknologi Malaysia, Johor Bahru, Johor

Malaysia

\section{PROCEEDINGS \\ VOLUME 3}

INNOVATION, ISSUES AND CHALLENGES FOR EDUCATIONAL SUSTAINABILITY 
Published by:

FACULTY OF EDUCATION, UNIVERSITI TEKNOLOGI MALAYSIA

Faculty of Education

Universiti Teknologi Malaysia

81310 Skudai, Johor, Johor Bahru

Malaysia

@ Faculty of Education, Universiti Teknologi Malaysia

All reserved. None of the publication of this proceeding can be republished or transferred in any means, electronically or mechanically such as copying, recording or storing for reproduction or accessed without the written consent from the holders of the rights.

All the papers in this proceeding are presented at the International Education Postgraduate Seminar 2014, 23 - 24 December 2014 at Universiti Teknologi Malaysia, Johor Bahru, Johor, Malaysia.

Perpustakaan Negara Malaysia Cataloguing-in - Publication Data

International Education Postgraduate Seminar (2014 : Johor Bahru, Johor) IEPS2014 International Education Postgraduate Seminar 2014: PROCEEDINGS INNOVATION, ISSUES AND CHALLENGES FOR EDUCATIONAL SUSTAINABILITY, VOLUME III, 23 - 24 December 2014, Universiti Teknologi Malaysia, Johor Bahru, Johor Malaysia / Edited by: Lokman Mohd Tahir, Aede Hatib Musta'amal, Azlina Mohd Kosnin, Halijah Ibrahim, Mohd Safarin Nordin, Sarimah Ismail, Najua Syuhada Ahmad Alhassora, Ana Haziqah A Rashid, Farhana Diana Deris, Mohd Rustam Mohd Rameli, Norhafizah Sulaiman, Nor Farhah Saidin.

\section{ISBN 978-967-12174-6-7}

1. Education, Higher-Malaysia - Congresses.

2. Educational change-Malaysia-Congresses. I. Lokman Mohd Tahir,.

II. Aede Hatib Musta'amal. III. Azlina Mohd Kosnin. IV. Halijah Ibrahim.

V. Mohd Safarin Nordin. VI. Sarimah Ismail. VII. Najua Syuhada Ahmad Alhassora. VIII. Ana Haziqah A Rashid. IX. Farhana Diana Deris.

X. Mohd Rustam Mohd Rameli. XI. Norhafizah Sulaiman. XII.

Nor Farhah Saidin. XIII. Tittle.

378.595 
Designed by:

Graphic Unit, Faculty of Education, UTM

Proofreaders:

Najua Syuhada Ahmad Alhassora

Ana Haziqah A Rashid

Edited by:

Lokman Mohd Tahir

Aede Hatib Musta'amal

Azlina Mohd Kosnin

Halijah Ibrahim

Mohd Safarin Nordin

Sarimah Ismail

Najua Syuhada Ahmad Alhassora

Ana Haziqah A Rashid

Farhana Diana Deris

Mohd Rustam Mohd Rameli

Norhafizah Sulaiman

Nor Farhah Saidin 
Assalamualaikum Wrt Wbt and warmest greetings!

In consonance with Universiti Teknologi Malaysia's aspiration to be recognised as a world class centre of academic and technological excellence through its commitment in enhancing innovative education and developing cutting-edge research while perfecting the technical and professional workforce of the nation, I am pleased that the Faculty of Education with strong support from its Postgraduate Student Society (PGSSFP) is organising the first International Education Postgraduate Seminar (IEPS2014).

One of the basic aims of research is to make human lives better, including the researchers themselves. To achieve this, researchers need to go beyond producing good dissertations. Research findings must be disseminated to become part of international literature to allow a more robust and condensed understanding of different phenomena in theoretical and practical avenues. Sharing research findings and future objectives of exploration via presentations and publications is essential in helping researchers enhance self-development, expand intellectual horizon, and acquaint with the publishing and sharing practices. Research cannot and should not be done in isolation; I hope this seminar will not only provide young and budding researchers a glimpse of the world of research that all academicians need to embrace but also foster connections and collaborations between researchers.

Seeing this seminar taking place gives me great pleasure. I applaud the concentrated efforts between lecturers, support staff and postgraduates at the Faculty. I am also very proud of all the presenters and participants who are part of the community of this first IEPS2014. This is indeed a great step forward for everyone!

Congratulations! 


\author{
Assalamualaikum Wrt Wbt and warmest \\ greetings!
}

It gives me great pleasure to welcome everyone to the International Education Postgraduate Seminar (IEPS2014).

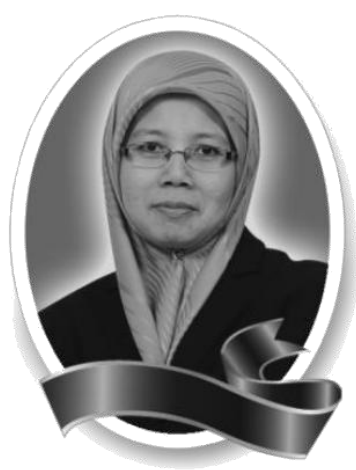

With the aim to transform all of research activities of the education postgraduates into an event of sharing and communication, IEPS2014 provides excellent opportunities for students to share initial findings and research directions and to receive helpful critique that will guide them towards better practices. This event will not only be helpful in informing research practices but will also be a contributor in developing students as future researchers and academicians.

The theme of this seminar, "Innovation, Issues and Challenges for Educational Sustainability" is most accurate to be brought forward because this theme signals the important shift in education. Be it in curriculum development, assessment, leadership, science education, vocational education, psychology, counseling, or multimedia education, the aims of research in education must be geared towards achieving educational sustainability.

To IEPS2014 Advisory and Organising Committee, I congratulate you for spearheading this FIRST International Education Postgraduate Seminar (IEPS2014). I would also like to express my sincere gratitude to the School of Graduate Studies for the generous grant, support and contribution. This appreciation also goes to everyone who have contributed in one way or another. Thank you for seeing the potentials of our postgraduates, for investing in their future, to inspire and to foster successful community.

To all delegates, presenters, and participants, this seminar is now all yours. I hope everyone will find the seminar inspiring and enriching, through discussions and networking with new acquaintances and colleagues. 


\section{FARHANA DIANA DERIS}

Assalamualaikum Wrt Wbt and warmest greetings! Welcome to the FIRST International Education Postgraduate Seminar!

In promoting educational sustainability, we need to take into account the context in which we live in,

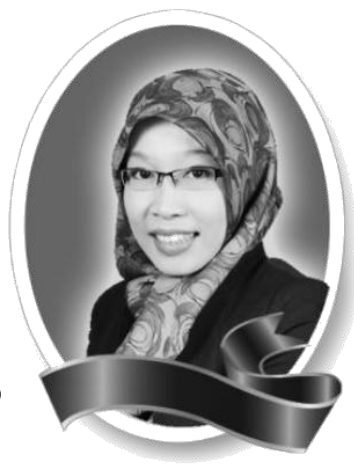
and the ways in which the world is interrelated; the society today lives in a world that is decisively supported and interconnected by technology. Embracing this monumental advancement, educational institutions need to produce world-class human capital with competent skills and intellectual capacity, commendable traits, values and attributes that are pertinent in the present and future context and necessary in thriving in this social and technological context.

This indeed highlights the importance of deliberation and exchange of ideas, experience and opinions in the pursuit of improving the different fields of education. Thus, this seminar, aptly themed, "innovation, issues and challenges for educational sustainability", is very timely. This seminar also captures the overarching role of multiple perspectives in informing practices, revolutionising the way teaching and learning are conceptualised, and inspiring new methodologies. Therefore, I hope this two-day seminar not only will enrich participants with research-related experiences but will also pave the way for fruitful dialogues and insightful deliberations towards achieving educational sustainability.

I would also like to take this opportunity to express my sincerest gratitude and appreciation to everyone who have contributed in one way or another to the success of this seminar, especially to the organising committee, the Postgraduate Student Society, Faculty of Education (PGSSFP). To all invited speakers, presenters and participants, thank you for your participation and support, without which this seminar would not have been possible.

See you again at the SECOND International Education Postgraduate Seminar! 


\section{IEPS2014 COMMITTEE}

Prof. Dr Baharuddin Aris

Patron

Assoc. Prof. Dr Muhammad Sukri Saud

Advisor

Dr Azlina Mohd Kosnin

General Chair

Dr Aede Hatib Musta'amal @ Jamal

Vice Chair

\section{ADVISORY COMMITTEE}

Dr Nor Fadila Mohd Amin

Dr Halijah Ibrahim

Dr Nor Hasniza Ibrahim

Pn Mulenawati Munawi

Assoc. Prof. Dr Lokman Tahir

Dr Mohd Safarin Nordin

Dr Sarimah Ismail

Assoc. Prof. Dr Noraffandy Yahaya

Dr M Al-Muz-Zamil Yasin

Dr Yusri Kamin

Dr Abdul Halim Abdullah

Dr Mahani Mokhtar

Dr Adibah Abdul Latif

Dr Noor Dayana Abdul Halim

Pn Siti Noraini Mohd Zali

Dr Norazrena Abu Samah

Dr Hasnah Mohamed
Secretary I

Secretary II

Treasurer \& PGSSFP Advisor

Assistant Treasurer

Papers and Publication

Papers and Publication

Papers and Publication

Technical, Equipment, and Broadcasting

Technical, Equipment, and Broadcasting

Logistics and Venue

Logistics and Venue

Protocol and Event Management

Certificate, Token and Honorariums

Publicity, Graphic and Montage

Publicity, Graphic and Montage

Website and Communication

Website and Communication

Dr Megat Aman Zahiri Megat Zakaria Website and Communication 


\section{ORGANISING COMMITTEE}

Farhana Diana Deris

Suraiya Haji Muhamad

Fatimah Sarah Yaacob

Crystal Joan Peter

Kho Pui Wun

Nur ‘Aqilah Mohd Norain

Norhafizah Sulaiman

Noor Izzati Ariff

Sponsorship \& Exhibition

Mohd Rustam Mohd Rameli

Nurul Sa'dah Saipuldin

Nor Farhah Saidin

Papers and Publication

Najua Syuhada Ahmad Alhassora

Ana Haziqah A. Rashid

Mohd Nur Al Sufi Romele

Publicity, Graphic and Montage

Nur Jannah Jamil

Logistics and Venue

Uzailun Nafais Zainal Abidin

Technical, Equipment, and Broadcasting

Sashendran A/L Vanarajan

Secretariat

Suhaimi Zakaria @ Othman

Latifah Abdul Raub

Protocol and Event Management

Muhammad Umar Khan

Norulbiah Ngah

Nurul Farhana Jumaat

Noor Azaref Naim

Rosidah Abdullah Sani

Zurina Hamid

Samira Nikian

Hazlin Haron

Miller Yong

Norashuha Tajuddin

Faridah Mat Nor

Siti Rahimah Mohd Yusop

Norhayati Ahmad

Rafaquat Ali

Ahmad Firdaus Abd Hadi

Siti Khadijah Lokman

Hafzan Ibrahim

Noriadah Abdul Karim

Diyana Zulaika Abdul Ghani
Organising Chairperson

Organising Vice Chairperson

Secretary III

Vice Secretary (Department of Technical and

Engineering Education)

Vice Secretary (Department of Educational Science, Mathematics and Creative Multimedia)

Vice Secretary (Department of Educational Foundation and Social Science)

Treasurer II

Vice Treasurer 


\section{TABLE OF CONTENTS}

ID NO.

TITLE

PAGE

2 Predicting Model of Academic Buoyancy: 1 The

Roles of Achievement Goals and Self-Regulation

Mohd Rustam Mohd Rameli, Azlina Mohd Kosnin

5 Pengaruh Kompetensi Keusahawanan 14 Terhadap Tingkahlaku Inovatif

Mohd. Asri Ispal, Mohd. Khata Jabor, Asnul

Dahar Minghat

19 A Myopic Comparative Review Between

27 Five-Factor Model And Hexaco Model Of Human Personality

Mahtab Ghadimi, Mohd Tajudin Ninggal Mohd Tajudin Ninggal

23 Holistic ApproachForCorrectional 38 Education In TVET: Hatching The Hace In Prison Education

Muhamad Afzamiman Aripin, Rohana Hamzah, Ros Eliana Ahmad Zuki, Akhmal Annas Hasmori

24 Designing Educational Simulation For 49 Impact Test Machine Ahmed Hadi Hatif Shubber, Amirmudin Bin Udin, Asnul Bin Minghat 
29 Perlaksanaan

Amalan

Kepimpinan

63

'Turnaround' Dalam Kalangan Pengetua

Sekolah Menengah Di Negeri Sabah

Irene Branda Macus, Khadijah Bt Daud

32 Internet Usage Among Undergraduate 76 Students In A Public University In Malasia $\mathrm{Lu} \mathrm{Xi}$, Yeo Kee Jiar

33 Meeting Supervisors' Expectations of 83 Undergraduates Final Year Project Reports Salawati Ahmad, Masputeriah Bte Hamzah

35 KeberkesananModulNilaiKelestarianDalam 94 TopikDayaTingkatanEmpat MohdFadhliZakaria, FatinAliahPhang

37 Construction On Molee Career Instrument (Mci) As Selection Tool In Allied Health Courses

Gooh Mo Lee, Syed Mohamed Shafeq Bin Syed Mansor, Yeo Kee Jiar, Yahya Buntat

40 The Need For Problem-Based Learning In

Nigerian Secondary Schools Chemistry Lessons

Abubakar Abbas Babayi, Mohammad YusofArshad

41 Cadangan Pembinaan Model Penghujahan 132 Saintifik Dalam Kimia Chuzairy Hanri, Mohammad Yusof Arshad

44 ESL Learners' English Learning Attitudes 146 In Chinese Independent High Schools Khei 
YokMan@ KheiYokLee, Noor Zainab Bt

Abdul Razak

50 Investigating The Existing Literary Text In

School: Students Perception About The

Need Of Criteria In Text Selection

Aryanti Ishak, Zaidah Zainal

51 The Corelation Between Psychological 166

Needs And Social Network Activities

Shima Mashayekhi, Mohd Tajudin Md.

Ningal

60 Pengetahuan Teknologi Guru Cemerlang 178 Fizik

ZarirahAbdul Hamid, FatinAliahPhang

62 Persepsi Majikan Terhadap Pekerja Bagi

Industri Pembuatan

Chua Siew Lian, Yusri Kamin

63 Pembentukan Item Instrumen Sistem 202

Kepercayaan Yang Salah: Suatu Kajian

Kualitatif

Mohd Nur Al Sufi Romele, Syed Mohammed

Shafeq Syed Mansor

64 Inculcation Of Values To Overcome

Disciplinary Problems In Skill-Based

Educational Institutions

Nor Aishah Abdul Aziz, Mohd Zolkifli Abd

Hamid

65 Generic Employability Skills Integration In

Technical And Vocational Education

Curriculum: A Requirement For The 
Preparation Of The 21st Century Workforce Azlan Abdul Latip, Muhammad Inti

66 Komitmen Kerja Pengetua Dalam 243

Melaksanakan Tugas Pada Sekolah

Menengah Pertama (Smp) Negeri Di Bandar

Padang

Syahril, Khadijah Binti Daud Daud

67 Assessment Practices And Physics 252 Epistemological Beliefs

Lee Ween Shin, Fatin Aliah Phang

72 Penerapan Strategi Pengutaraan Masalah 265

Untuk Meningkatkan Kemahiran Berfikir

Aras Tinggi

MuniandyVinogharri, JohariSurif

74 Patterns Of Teaching Approach Adopted By 291

Preservice Teachers In Teaching Writing

Sarala@Thulasi Palpanadan, Fauziah

Ismail, Abdul Rahim

80 Stail Pembelajaran Guru Pelatih Dalam 304

Praktikum Latihan Mengajar

Nur'Ain Baharin, Mohd Zolkifli Abd Hamid, DayanaFarzeeha Ali

84 The Socratic Method Online To Improve 319 Critical And High Order Thinking Among Students

Salihuddin Md. Suhadi, Hasnah Mohammed, Norasykin Mohd.Zaid, Zaleha Abdullah, Baharuddin Aris

87 Difficulties

Of

Implementing

325 
Communicative Language Teaching (Clt) In Malaysia

Samira Nikian, Faizah Mohamad Nor

92 A Framework Of Scenario-Epistemic Game

For Proffesional Skills And Higher Order

Thinking Skills

Kho Pui Wun, Jamalludin Harun

96 Conceptual Framework Of Video Learning

Based On Popbl

Cbe Khairul Anuar Abdul Rahman, Muhammad Sukri Saud, Yusri Kamin, Norazrena Abu Samah

100 Persepsi Pelajar Sekolah Berasrama Penuh (Sbp) Terhadap Mata PelajaranFizik NurHazwaniZakaria, Mohamad Bilal Ali

102 Mengenal pasti Kesan Pendidikan 385 Keusahawanan Pada Pelajar Kejuruteraan Ahmad Firdaus Abd Hadi, Khata Jabor, DayanaF arzeha Ali

106 Personality Traits And Life Satisfaction: A Study Among Students In A Public University

Seyedeh Maryam Geramian, Mohd Tajudin Ningal

107 Task Induced Involvement:The Issue Of 408 Reactivity On The Development Of Vocabulary: A Review Paper Halah Abdulelah Mohammed, Norazman Abdul Majid, Tina Abdllah 
109 The Study Of Argumentative Knowledge

Construction In Web 2.0 Learning

Environment Towards Students' Critical

Thinking Skills

Siti Nur Khadijah Aishah Ibrahim,

Jamalludin Harun

114 Pendidikan Teknikal Dan Latihan 435

Vokasional Ke Arah Pemupukan Kemahiran

Generik Hijau

Nadia Hartini Mohd Adzmi, Mohd Zolkifli

Abd Hamid, Yusri Kamin

121 Employing Written Corrective Feedback In

Teaching Writing

Ng Siew Fong, Wan Fara Adlina Wan

Mansor, Abdul Rahim Haji Salam

122 Amalan Kepimpinan Tranformasi Guru

451

Besar Dan Impaknya Terhadap Komitmen

Guru Sekolah Rendah Di Negeri Sabah

Faridah Mat Noor, Khadijah Bt Daud

124 Pendekatan Konteks Pengguna Dalam 470

Rekabentuk Persekitaran Pembelajaran

Secara Talian Terus

Nur Syamimi Mohd Razali, Noraffandy

Yahaya

125 Kompetensi Pengetua Dan Pengurusan 474

Perubahan Di Sekolah

Kalithasan Muniandy, M.Al-Muzzammil Yasin

126 Mengkaji Kemahiran Berfikir Kritis Dan Pencapaian Pelajar Menerusi Persekitaran 
Pembelajaran Kolaboratif Berbantukan

Komputer Bagi Subjek Bahasa

Pengaturcaraan

Siti Mastura Baharudin, Jamalludin Harun

129 Fostering Problem Solving In Chemistry: 507 The Importance, Difficulties And The Needs

Of Scientific Creativity

SitiSalbiah Omar, Noor Dayana Abdul

Halim, JohariSurif, JamalludinHarun

131 Penghasilan Video Interaktif Bagi Pengujian 520

Ketangkasan Reaktif Khusus Untuk

Permainan Bola Jaring

NurEzzainiMohd Nor, Halijah Ibrahim

142 RobotikDalamPendidikan Di Malaysia

Hafzan Ibrahim, Mohamad Bilal Ali,

FatinAliahPhang, Norazrena Abu Samah

145 Conceptual Changes In Scientific 539

Argumentation Through Guided Group

Settings

Heng Lee Ling, Johari Surif,Seng Cher Hau

146 Concept Map As an Alternative Assessment in Laboratory Activities

Intan Baizura A Ghani, Noraffandy Yahaya, Nor Hasniza Ibrahim, Mohamed Noor

Hassan

149 Quantitative Research on Education For

Sustainable Development (Esd) Practices

Among Malaysian Polytechnics

Crystal Joan Peter, Wilfredo Libunao 
152 Parental Monitoring On The Adolescence

Development

Normalis Bazid, Zainudin Abu Bakar

154 Kerangka Konseptual Kesediaan Guru 591 Dalam Melaksanakan Pentaksiran

Berasaskan Sekolah (PBS) Di Sekolah

Menengah Semenanjung Malaysia

SivakkumarBalakrishnan, Muhammad Sukri

Saud

156 Tinjauan Masalah Pengurusan Proses PBS 605

Dan Ciri-Ciri Elemen Pentaksiran Yang

Perlu Ada Dalam Satu Sistem Pengurusan

Eportfolio PBS

Suhaizal Hashim, Jamalludin Harun

162 Pendekatan Pembelajaran Berasaskan

Konteks Untuk Memupuk Literasi Sains

dalam Bilik Darjah

Latifah Abdul Raub, Muhammad Yusof

Arshad, Nurbiha A.Shukor

168 Chemical Problem-Solving Competency Of

Open-Ended Problems Aiming To Improve Higher Order Thinking Skills(HOTS):

Authentic Practice Suraiya Muhamad, Jamalludin Harun, Johari Surif, Noor Dayana Abdul Halim

171 Menggalakkan Kemahiran Pemodelan 646 Pelajar Dalam Kimia Menggunakan Process Oriented Guided Inquiry Learning (Pogil) Siti Zubaidah Omar, Muhammad Yusof Arshad, Mohd Shafie Rosli, Nurbiha A.Shukor 
173 Impak Personaliti Pengetua Terhadap 656 Prestasi Sekolah Di Smp Sulawesi Selatan Indonesia

Usman Baharuddin, Khadijah Binti Daud

174 E-Learning Environment For Deaf Students 666

In Learning Science: A Theoretical

Framework

Mohd Hisyamuddin Mohd Hashim, Zaidatun

Tasir

176 Pelaksanaan Pembelajaran Berasaskan 677

Projek (PjBL) Di Politeknik Malaysia. Satu

Kajian Awal

Mohd Noramdzan Mohd Yusof, Aede Hatib

Musta'amal, Nor Salwa Ismail

180 Factors Causing Secondary Students 688

Involved In Loitering

Gan Lui Nam, Yeo Kee Jiar

184 Kesan Pengurusan Pengetahuan Dan 695

Mediator Budaya Sekolah Ke Atas

Keberkesanan Pengurusan Sekolah

Tee Bee Tin, Dr. Khadijah binti Daud

185 Kaedah Pengajaran Pendidikan 708

Keusahawanan: Suatu Kajian Literatur

Roziati Sumin, Yahya Buntat, Siti Suhaila

Samian, Normala Rahmat

191 The Impact Of Teaching Strategies And

Chinese Language Learning In National School

Ng Sar Ee, Yeo Kee Jiar 
192 Pengaruh Amalan Nilai Kendiri Pengetua

Terhadap Sikap Kerja Dan Disiplin Kerja Muhammad Asri, Lokman Mohd Tahir

193 The Level And Causes Of Stress Intention

To Resign Working Among Geography

Teachers In A District In Malaysia

Shahrudin Jemaat, Irkhaniza Md Rahim,

Syed Mohamed Syafeq Mansor

195 Pembelajaran Berasaskan Projek (PBP) Dan

Pendidikan Abad Ke-21

Mazlan Setapa, Mohamad Bilal Ali, Fatin

Aliah Phang, Abd Khamim, Ismail

197 Psikospiritual Islam Dan Kesan Aplikasinya 767 Dalam Kehidupan Manusia

202 Modul Pengajaran Sains Topik "Nutrisi" 778

Berteraskan Model Konstruktivis Bersepadu Zainab binti Jelani jelani, Johari bin Surif Surif

207 Pengaruh Kepimpinan Instruksional Guru 795 Besar Dan Efikasi Kolektif Guru Terhadap Komitmen Organisasi Guru Khadijah Daud, Hafizuddin Md Shakhih

215 Kriteria Pengajaran Dan Pembelajaran 814 Kursus Pendidikan Vokasional Yang Dapat Membangunkan Pemikiran Aras Tinggi Pelajar

Nurzalina Hashim, Muhammad Sukri Saud 
218 Strategi Pengajaran Sains Berasaskan 823

Epistemologi Saintifik

Mohamad Faqih Junus, Fatin Aliah Phang

219 Epistemology, Scientific Epistemology, 842

Epistemology Move: A Review

Muhammad Hidayat Ishak, Fatin Aliah

Phang

221 Transformasi Psikologi Diri Pensyarah IPG

Menerusi Aplikasi Profil Personaliti Tajma

Hasbullah Abukassim, Mohd Tajudin

Ninggal Mohd Tajudin Ninggal

225 Pembelajaran Berasaskan Masalah Dalam 862

Sains:Satu Meta Analisis

Mohd Mokhzani Ibrahim, Mohammad Yusof

Arshad, Nurbiha A.Shukor, Mohd Shafie

Rosli

227 Perbandingan Kurikulum Sains (KBSM) 876

Dengan Pendidikan Saintis Muslim Zaman

Kegemilangan Islam

Nurhasyimah Ismail, Norhasniza Ibrahim

234 Floating Facilitation in Malaysian Chemistry 891 Pbl Lesson

Tan Yin Peen, Mohammad Yusof Arshad

237 Teknik Pembelajaran Tilawah Al-Qur'an Di 907 Era ICT

Noor Azaref Naim, Jamalludin Harun

238 Chemistry Teachers' Understanding Of 922 Models Of Teaching And Learning In Practical Work 
Oi Lee Jenny Cheng, Mohammad Yusof Arshad,

242 Cognitive Ability And Academic 935 Achievement Of UndergraduatesIn Universiti Teknologi Malaysia Chong Yi Long, Yeo Kee Jiar

245 Investigation of Efl Adults Motivation 950 toward Using Commercial Computer Games to Learn English Language Elham Mahmoudi, Adlina Bt Samad

247 Criteria For Selecting Bulding Technology 965 Students For Creative Thinking Skill Acquisition In Nigeria Technical Colleges Jonathan Ojo Oke, Aede Hatib Musta'amal

252 Development Of Matter Concept On Submicroscopic Level Across Ages Nurdiana Abdullah, Johari Bin Surif 


\title{
KOMITMEN KERJA PENGETUA DALAM MELAKSANAKAN TUGAS PADA SEKOLAH MENENGAH PERTAMA NEGERI DI BANDAR PADANG
}

\author{
Syahril \& Khadijah Daud
}

\begin{abstract}
ABSTRAK
Komitmen merupakan faktor penentu kejayaan pengetua dalam memimpin suatu sekolah. Kajian ini bertujuan untuk mengenal pasti corak komitmen kerja Pengetua pada Sekolah Menengah Pertama Negeri di Bandar Padang dalam melaksanakan tugas. Kajian ini berbentuk deskriptif. Populasi pada kajian ini adalah Pengetua pada Sekolah Negeri di Bandar Padang yang berjumlah sebanyak 37 orang, kerana populasi kecil atau sedikit, maka semua populasi dijadikan responden pada kajian ini. Instrumen kajian menggunakan Soal Selidik skala lima mata. Keboleh percayaan soal selidik Alfa Cronbanch 0,96. Manakala pengolahan data hanya dilakukan dengan mencari purata. Dapatan pengolahan data pada kajian ini memperolehi bahawa komitmen afektif pengetua sekolah dalam melaksanakan tugas cukup tinggi iaitu 3,83 dari skala 5, ertinya pengetua telah memiliki komitmen afektif dalam melaksanakan tugas. Komitmen berketerusan dengan purata 4,12 ertinya dalam melaksanakan tugas di sekolah pengetua sudah memiliki komitmen berketerusan. Manakala purata komitmen
\end{abstract}


normatif pengetua dalam melaksanakan tugas adalah 4,02 ini juga mempunyai erti bahawa pengetua juga sudah memiliki komitmen normatif dalam melaksanakan tugas. Secara amnya boleh disimpulkan bahawa Pengetua pada Sekolah Menengah Pertama Negeri di Bandar Padang telah memiliki komitmen yang cukup tinggi dengan purata 3,99 dalam melaksanakan tugas pada sekolah yang dipimpinnya, namun masih perlu penyempurnaan dan diperingkatkan lagi.

Kata Kunci: Komitmen; afektif, Berketerusan, Normatif; pengetua

\section{PENGENALAN}

Banyak hasil kajian menunjukkan bahawa pendidikan merupakan faktor penentu kemajuan suatu bangsa, jika suatu bangsa berjaya membina dasar-dasar pendidikan kebangsaan dengan baik, maka akan memberi kesan kepada kemajuan di bidang lain. Kejayaan di bidang pendidikan ditentukan oleh banyak faktor, salah satunya adalah faktor pengetua. Yukl, 2006 dan Kouzes Posner, 2003 mengemukakan pengetua sebagai pemimpin di sekolah merupakan unsur utama yang amat menentukan kejayaan sekolah. Kualiti sekolah amat bergantung kepada kualiti pengetua pada sekolah tersebut. Hussien, 2007, mengemukakan pengetua merupakan pemangkin kepada kecermelangan sekolah. Hal ini juga disokong oleh Levin dan Lockheed (2001), yang mengatakan bahwa maju dan cemerlangnya sebuah sekolah adalah diterajuni oleh pengetua yang berkesan. Oleh kerana itu, tidak ada sekolah yang menjadi maju dan cemerlang sekiranya kepemimpinan pengetua pada sekolah tersebut adalah lemah (Dessler, 2005). Sebaliknya sekolah yang lemah boleh bertukar menjadi sekolah yang berkesan dan berjaya dengan adanya kepemimpinan pengetua yang berkualiti, (Hussien, 2007).

Sebagai pimpinan di sekolah pengetua memiliki beberapa peran dalam melaksanakan tugas iaitu sebagai educator, maneger, administrator, supervisor, lieder, inovator dan motivator (Mulyasa, 
2013). Kejayaan pengetua untuk melaksanakan tugas dan peran tersebut dipengaruhi oleh banyak faktor, satu dari faktor tersebut adalah komitmen kerja pengetua dalam melaksanakan tugas.

Komitmen kerja merupakan faktor penentu kejayaan pengetua dalam memimpin sekolah. Newstrom (2007) mentakrifkan komitmen kerja boleh diertikan, sebagai kesetiaan pegawai terhadap sejauh mana fasa atau darjah pengenalan diri pegawai pada pekerjaan dan keinginan-keinginannya untuk meneruskan penyertaan aktifitinya dalam organisasi dimana dia berada. Sedangkan Feldman (2000) menyatakan, bahawa komitmen kerja adalah kecenderungan seseorang untuk melibatkan diri ke dalam apa yang dikerjakan dengan keyakinan bahawa aktiviti yang dikerjakan penting dan bermakna. Kedua-dua pendapat di atas pada asasnya mempunyai pandangan yang sama tentang komitmen yaitu fasa keterikatan pegawai terhadap tugasnya. Sementara itu, Greenberg dan Baron (2009) berpendapat bahawa komitmen organisasi adalah sikap konsisten individu terhadap organisasi di mana mereka bekerja. Sikap tersebut adalah sikap konsisten individu terhadap mana mereka terlibat dengan pekerjaan mereka dan tertarik untuk mempertahankan pekerjaannya. Selari dengan itu Anthony (2009) mengemukakan komitmen kerja adalah adalah penerimaan seseorang terhadap nilai pekerjaan atau bidang pekerjaan yang dipilihnya, dan keinginan nutuk mempertahankan kedudukan dalam tugas tersebut. Komitmen ada ketika manusia mempunyai peluang untuk menentukan apa yang akan dilakukan. Komitmen terhadap pekerjaan dikonseptualisasikan sebagai hubungan psikologi antara orang dan pekerjaan yang terlibat berasaskan pada reaksi afektif terhadap pekerjaan itu. Robbins (2003) mengemukakan orang yang mempunyai komitmen terhadap pekerjaan, akan bekerja secara total dalam organisasi dengan memberikan segenap perhatian, fikiran, tenaga dan masa yang dimilikinya untuk bekerja sehingga mencapai hasil yang optimum. Sebaliknya orang yang tidak mempunyai komitmen, meskipun dia mempunyai kompetensi yang bagus, dia akan bekerja setengah hati. Komitmen mempunyai hubungan dengan kesetiaan, ketaatan dan kepuasan kerja dalam organisasi. Orang yang berkomitmen 
tinggi lebih mementingkan pekerjaan dan tugas dalam memenuhi kemahuan organisasi berbanding keperluan sendiri.

Orang yang memiliki komitmen kerja menurut Goleman (1999) mempunyai ciri-ciri sebagai berikut (a) mempunyai inisiatif untuk mengatasi masalah yang muncul, semada yang berhubungan secara langsung dengan dirinya mahupun kumpulannya, (b) bernuansa emosional, iaitu membuat sasaran individu dan sasaran organisasi menjadi satu atau sama sehingga mereka merasakan keterikatan yang kuat terhadap organisasi atau pekerjaan, (c) bersedia melakukan pengorbanan atau berkorban apabila diperlukan, (d) mempunyai visi strategik yang tidak mementingkan diri sendiri, (e) bekerja secara sungguh-sungguh walaupun tanpa ganjaran secara langsung, (f) merasa sebagai pemilik atau memandang diri sebagai pemilik sehingga setiap tugas diselesaikan secepat dan sebaik mungkin, (g) mempunyai rumusan misi dan visi yang jelas sebagai gambaran terhadap apa yang akan dicapai, dan

(h) mempunyai kesedaran diri dengan perasaan yang jernih bahawa pekerjaan bukanlah suatu beban, tetapi merupakan kesenangan hobi yang dilakukan. Ciri-ciri di atas merupakan penentu bahawa pada diri seseorang terdapat komitmen dalam melaksanakan pekerjaan. Sementara itu Joseph (2002) mengemukakan beberapa ciri-ciri orang yang mempunyai komitmen kerja dalam organisasi iaitu, (a) mempunyai kepercayaan dan sokongan yang tinggi terhadap nilai dan pekerjaan, (b) mempunyai keinginan berusaha yang sungguh-sungguh untuk melaksanakan pekerjaan dalam organisasi, (c) mempunyai keinginan untuk melaksanakan kerja dengan baik dan memelihara keahlian organisasi, (d) mempunyai keinginan kuat untuk tetap jadi ahli organisasi, (e) kesediaan untuk tetap berusaha sebaik mungkin demi kepentingan organisasi, dan

(f) kepercayaan dan penerimaan yang kuat terhadap nilai dan tujuan organisasi.

Hasilan kajian Nurliana (2011), mendapati bahawa komitmen kerja pengetua di lingkungan Kementerian Pendidikan dalam melaksanakan tugas masih dalam katagori rendah. Sedangkan Imam Subandi (2012), menyatakan bahawa komitmen kerja pengetua dalam melaksanakan tugas masih jauh dari yang 
diharapkan. Rendahnya komitmen kerja pengatua dalam melaksanakan tugas terlihat dari kurangnya kerjasama pada sekolah yang dipimpinnya, rendahnya tanggungjawab dan kurangnya disiplin pengetua dalam melaksanakan tugas. Seperti kerapnya pengetua meninggalkan sekolah untuk melakukan pekerjaan yang kurang terkait dengan tugasnya di sekolah, kurangnya pengawasan dan pembinaan yang mereka lakukan semada terhadap pelajar mahupun terhadap cikgu sehingga kerap terjadi konflik di sekolah, rendahnya disiplin di sekolah, hasilan belajar siswa masih belum mencapai standard yang diharapkan. Akibat dari permasalahan tersebut (rendahnya komitmen kerja pengetua sekolah) kerap terjadi unjuk perasaan yang dilakukan cikgu dan pelajar, mereka menuntut agar pengetua mundur dari kedudukannya atau berhenti daripada pengetua, (Wahjosumidjo 2013). Hal tersebut jelas akan mengganggu kenyaman kegiatan pembelajaran dan keberhasilan penyelenggaraan pendidikan di sekolah untuk itu komitmen kerja pengetua dalam pengurusan sekolah harus dipertingkatkan.

\section{METODOLOGI}

Kajian ini hanya berbentuk deskriptif, dengan populasi kajian adalah Pengetua pada Sekolah Menengah Pertama (SMP) Negeri di Bandar Padang yang berjumlah sebanyak 37 orang. Kerana populasi tidak begitu banyak atau besar (hanya 37 orang), maka pada kajian ini tidak dilakukan pengambilan sampel, dengan lain kata semua populasi dijadikan responden pada kajian ini.

Pengumpulan data dilakukan dengan menggunakan instrumen dalam bentuk soal selidik yang disusun berdasarkan skala lima mata. Jumlah soal selidik untuk mengukur komitmen afektif sebanyak 11 item, soal selidik untuk mengukur komitmen berketerusan sebanyak 11 item dan soal selidik untuk mengukur komitmen normatif sebanyaak 10 item.

Hasil kajian rintis terhadap soal selidik didapatkan data bahawa 
soal selidik yang digunakan pada kajian ini memiliki keboleh percayaan yang cukup tinggi dengan Alfa Cronbanch 0,96. Manakala pengolahan data hanya dilakukan dengan mencari purata dari masing-masing aspek yang dikaji (komitmen afektif, komitmen berketerusan dan komitmen normatif).

\section{DAPATAN KAJIAN DAN PERBINCANGAN}

Kajian yang telah dilakukan tentang komitmen kerja Pengetua pada Sekolah Menengah Pertama (SMP) Negeri di Bandar Padang, menunjukkan bahawa komitmen kerja pengetua sekolah sudah cukup tinggi, semada komitmen afektif, komitmen berketerusan, mahupun komitmen normatif. Untuk lebih jelasnya boleh dilihat pada tabel berikut.

Jadual 1. Dapatan Kajian tentang Komitmen Kerja Pengetua

\begin{tabular}{|c|l|c|}
\hline No & \multicolumn{1}{|c|}{ Bentuk Komitmen Kerja } & Purata skor \\
\hline 1 & Komitmen afektif & 3,83 \\
\hline 2 & Komitmen berketerusan & 4,12 \\
\hline 3 & Komitmen normatif & 4,02 \\
\hline & Purata & 3,99 \\
\hline
\end{tabular}

Data pada jadual di atas, menunjukkan bahawa komitmen afektif pengetua yang terkait dengan keterikatan emosional, identifikasi dan keterlibatannya untuk melaksanakan pekerjaan dalam organisasi cukup tinggi iaitu 3,83 ertinya pengetua telah memiliki komitmen afektif dalam melaksanakan tugas. Pengetua yang memiliki komitmen afektif yang tinggi dalam melaksanakan pekerjaan akan terus bekerja dalam organisasi, hal ini disebabkan kerana mereka memang ingin (want to) untuk melaksanakan melakukan pekerjaan tersebut, Greenberg dan Baron (2009).

Komitmen berketerusan dengan purata 4,12. Hal ini bererti Pengetua pada Sekolah Menengah Pertama Negeri Bandar Padang sudah memiliki komitmen berketerusan dalam melaksanakan 
tugas. Komitmen berketerusan berkaitan dengan pertimbangan untung rugi yang dirasakan atau didapatkan pengetua untuk tetap bekerja atau meninggalkan pekerjaan. Pengetua yang bekerja berasaskan komitmen berketerusan bertahan (kekal) dalam organisasi untuk melaksanakan pekerjaan sebab mereka ingin (need to) untuk melakukan hal tersebut kerana tidak ada pilihan lain.

Manakala purata komitmen normatif pengetua dalam melaksanakan tugas adalah 4,02 ini juga mempunyai erti bahawa pengetua juga sudah memiliki komitmen normatif dalam melaksanakan tugas. Komitmen normatif berkaitan dengan perasaan nilai ataupun norma yang ada pada diri pengetua untuk tetap (kekal) menjadi sebahagian daripada pekerjaan kerana kerana bekerja merupakan kewajiban yang harus dilakukan pegawai. Berasaskan dapatan kajian ini boleh disimpulkan bahawa pada amnya Pengetua pada Sekolah Menengah Pertama Negeri di Bandar Padang telah memiliki komitmen yang cukup tinggi dalam melaksanakan pekerjaan.

Walaupun pada amnya hasil kajian ini manunjukkan bahawa pengetua pada Sekolah Menengah Pertama (SMP) Negeri Bandar Padang sudah cukup tinggi, namun masih perlu disempurnakan atau dipertingkatkan agar kejayaan pada sekolah yang dipimpinnya boleh dicapai, baik pada aspek komponen komitmen afektif, berketerusan mahupun pada aspek komitmen normatif.

\section{KESIMPULAN}

Berasaskan dapatan pada kajian ini dapat disimpulkan bahawa komitmen kerja pengetua pada Sekolah Menengah Pertama Bandar Padang masih belum memuaskan dan masih perlu diperingkatkan, baik komitmen afektif, berketerusan dan komitmen normatif. Hal ini dilakukan untuk mencapai kejayaan pada sekolah yang dipimpin oleh pengetua. 


\section{RUJUKAN}

Anthony, Gary Dworkin. (2009). International Handbook of Research on Teachers and Teaching. New York: Springer.

Dessler,Garry. (2005). Manajemen Personalian (terjemahan Agus Dharma). Edisi Ketiga. Jakarta: Erlangga.

Feldman, Robert S. (2000). Adjustment Applying Psychology in a Complex Word. New York: McGraw-Hill Book Company.

Greenberg, Jerald and Robert A. Baron. (2009). Behavior in Organizations. Upper Saddle River. New Jersey: Pearson Education, Inc.

Goleman, Daniel. (1999). Kecerdasan Emosi untuk Mencapai Puncak Prestasi. Terjemahan Alex Tri Kantjono Widodo. Jakarta: Gramedia.

Hussein Mahmood. (1997). Kepemimpinan dan Keberkesanan Sekolah. Kuala Lumpur: Dewan Bahasa dan Pustaka.

Imam Subandi. (2012). Pengaruh Komitmen Tugas, Pemberdayaan dan Motivasi Kerja terhadap Kinerja Pengawas Sekolah. (disertasi). Jakarta: Pasca Sarjana UNJ.

Joseph, Linz Susan J. (2002). Job Satisfaction Among Russian Workers. William Davidson Institute Working Paper, Reseacrh Feelow Wlliam Davidson Institute University of Michigan.

Kouzes, James M., Barry Z. Posner. (2003). Leadership the Challenge.

San Francisco: Jossey-Bass, A Wiley Imprint.

Lockheed, ME \& Levin HM. (2001). Creating Effective Schools. Edisi.

Washington DC: Falmer Press.

Mulyasa. (2013). Kepala sekolah yang Profesional. Bandung: Alfabeta. Newstrom, John W. (2007). Organizational Behavior. Human Behavior at Work. New York: McGraw-Hill.

Nurliana. (2011). Pengaruh Budaya Organisasi, Kepemimpinan, Kepuasan Kerja dan Motivasi Berprestasi terhadap Komitmen Organisasi Kepala-kepala SDN di Kota Palembang. (disertasi). Jakarta: Pasca sarjana UNJ.

Robbins, Stephen P. (2003). Organizational Behavior. New Yersey: Prentice-Hall International, Inc.

Wahjosumidjo. (2013). Kepemimpinan Kepala Sekolah. Jakarta: Raja Grafindo Persada.

Yukl, G., \& Michel, J. (2006). Proactive Influence Tactics and LeaderMember Exchange. In C. A. Schriesheim and L. Neider (Eds.). 
Power and Influence in Organizations: Research in Management. Greenwich, CT: Information Age Publishing. 
